Check for updates

Cite this: Phys. Chem. Chem. Phys., 2017, 19, 24742

\section{A new insight into the thermodynamical criterion for the preparation of semiconductor and metal nanocrystals using a polymerized complexing method $\dagger$}

\author{
Pingyun Li, ${ }^{\star a}$ Qingqing Wang, ${ }^{a}$ Guodong Deng, ${ }^{a}$ Xiaode Guo, ${ }^{a}$ Wei Jiang, ${ }^{a}$ \\ Hongying Liu, ${ }^{a}$ Fengsheng $\mathrm{Li}^{\mathrm{a}}$ and Nguyen Thi Kim Thanh (D) *bc
}

\begin{abstract}
This work reports the intrinsic thermodynamical criterion for the preparation of metal and semiconductor nanocrystals using a polymerized complexing method. The basic principle of this method is the formation of a polymerized complexing structure between mono-, binary-, or ternary-metallic ions and bonding agents in aqueous or ethylene glycol solutions by evaporation of the solvents. Heat treatment of the complexing structure under $\mathrm{N}_{2}$ atmosphere produces $\mathrm{H}_{2}$ and $\mathrm{CH}_{4}$ gases, which can reduce the oxide crystalline nuclei to semiconductor and metallic nanocrystals. Experimental results show that $\mathrm{Te}, \mathrm{CdTe}$, $\mathrm{Ag}_{2} \mathrm{Te}$, CuTe, NiTe ${ }_{1.5}, \mathrm{CoTe}_{1.5}, \mathrm{Bi}_{2} \mathrm{Te}_{3}, \mathrm{Sb}_{2} \mathrm{Te}_{3}, \mathrm{Bi}-\mathrm{Sb}, \mathrm{In}_{2} \mathrm{Te}_{3}, \mathrm{Ni}_{2.9} \mathrm{SnTe}_{2}, \mathrm{CuGaTe}$, and CulnS 2 semiconductors and $\mathrm{Bi}, \mathrm{Sb}, \mathrm{Ag}, \mathrm{Cu}$, and $\mathrm{Ni}$ metallic nanocrystals can be prepared by this method. Transmission electron microscopy observations show that the obtained $\mathrm{Bi}, \mathrm{Ag}_{2} \mathrm{Te}, \mathrm{Bi}_{2} \mathrm{Te}_{3}, \mathrm{Sb}_{2} \mathrm{Te}_{3}, \mathrm{CdTe}$, and $\mathrm{NiTe}_{1.5}$ nanocrystals have grain sizes in the nanometer range. The types of metallic and semiconductor phase that can be obtained by this method are explained by the thermodynamical criterion based on calculations of the Gibbs free energy and electrode potential. It is proposed that the crystalline phase of the final product is controlled by the change of the Gibbs free energies of the reactions of the metal oxide with reducing gases and the metal oxide redox electrode potentials, not the metal redox standard electrode potentials and electronegativities of the elements. Furthermore, a prediction is presented for the preparation of other kinds of binary and ternary compound based on the thermodynamical criterion. Our results provide new insight into facile and green preparation of semiconductor and metal nanocrystals.
\end{abstract}

Received 18th June 2017, Accepted 13th August 2017 DOI: $10.1039 / c 7 c p 04097 k$

rsc.li/pccp
NCs is the hot-injection process where $\mathrm{Cd}\left(\mathrm{CH}_{3}\right)_{2}$ and trioctylphosphine selenide (TOPSe) or trioctylphosphine telluride (TOPTe) are treated in organic solutions, ${ }^{9,10}$ which are detrimental to the environment. ${ }^{11}$ Metallic NCs are often prepared by a reducing process in aqueous solution using typical reducing agents such as borohydride ${ }^{12}$ or hydrazine, ${ }^{13}$ which are also hazardous. ${ }^{14}$ Citric acid (CA) can also be applied as a weak reducing agent to reduce noble metal ions of $\mathrm{Pd}^{2+}, \mathrm{Ag}^{+}$, and $\mathrm{Pt}^{4+} \cdot{ }^{15-17}$ In general, the standard electrode potential of a reducing agent should be lower than that of metallic ions (metal redox potential) so that the metallic ions can be reduced in solution directly, ${ }^{18}$ and it seems that metallic NCs can not be prepared when the standard electrode potential of the reducing agent is higher than the metal redox potential.

Recently, we reported a polymerized complexing method for the preparation of metallic NCs using inorganic metallic salts, starch, and de-ionized water as the initial chemicals. ${ }^{19}$ The metallic ions and starch formed a polymerized complexing structure after evaporation of the solvent. ${ }^{19}$ Then the dried polymerized complexing structure was calcined under $\mathrm{N}_{2}$ atmosphere, 
and monometallic $\mathrm{Ni}, \mathrm{Cu}, \mathrm{Ag}, \mathrm{Pd}$, and $\mathrm{Pt}$ or bimetallic $\mathrm{Cu}-\mathrm{Pt}$ and Ni-Pt NCs could be obtained. This method avoids high boiling point organic solvents and toxic chemical agents. However, the underlying mechanism for the formation of metallic NCs prepared by this method is not well understood, therefore it is necessary to explore an intrinsic rule for the explanation of the formation mechanism and present a prediction for the preparation of other metallic NCs. In this article, we report a general criterion for the preparation of semiconductor and metallic NCs using this method from a thermodynamical point of view for the first time. Based on calculation of the change of Gibbs free energy $\left(\Delta_{\mathrm{f}} G_{\mathrm{m}}^{\varnothing}\right)$ and electromotive force of a chemical reaction, the criterion can explain and predict the types of metallic, binary metallic, and semiconductor NC that can be obtained by this method. Moreover, the thermodynamical criterion is verified by experimental results where typical CdTe, Te, Bi-Sb, NiTe ${ }_{1.5}$, CuTe, Ag $\mathrm{Ag}_{2} \mathrm{Te}, \mathrm{Bi}_{2} \mathrm{Te}_{3}, \mathrm{Sb}_{2} \mathrm{Te}_{3}, \mathrm{In}_{2} \mathrm{Te}_{3}$, $\mathrm{Ni}_{2.9} \mathrm{SnTe}_{2}, \mathrm{CuGaTe}_{2}$, and CuInS ${ }_{2}$ semiconductor NCs as well as $\mathrm{Ni}, \mathrm{Cu}, \mathrm{Ag}, \mathrm{Bi}$, and $\mathrm{Sb}$ metallic NCs can be obtained by this environmentally benign polymerized complexing method. Based on this criterion, it is suggested that metallic and semiconductor NCs can also be obtained during heat treatment when the standard electrode potential of the reducing agent is higher than the metal redox potential, which is contrary to conventional reducing processes where the standard electrode potential of the reducing agent should be lower than the metal redox potential. Instead, the reducing agent serves as a bonding agent in solution because the reducing ability is prohibited, and the metal oxide redox potential rather than the metal redox potential is responsible for the formation of the semiconductor and metallic NCs.

\section{Experimental}

$\mathrm{Ni}\left(\mathrm{NO}_{3}\right)_{2} \cdot 6 \mathrm{H}_{2} \mathrm{O}(98.5 \%), \mathrm{Cu}\left(\mathrm{CH}_{3} \mathrm{COO}\right)_{2} \cdot \mathrm{H}_{2} \mathrm{O}(98 \%), \mathrm{Bi}\left(\mathrm{NO}_{3}\right)_{3} \cdot 5 \mathrm{H}_{2} \mathrm{O}$ (99\%), $\mathrm{Sb}\left(\mathrm{CH}_{3} \mathrm{COO}\right)_{3}(99 \%), \mathrm{Cd}\left(\mathrm{CH}_{3} \mathrm{COO}\right)_{2} \cdot 3 \mathrm{H}_{2} \mathrm{O}(99 \%), \mathrm{H}_{6} \mathrm{TeO}_{6}$ (98\%), $\mathrm{AgNO}_{3}$ (99\%), $\mathrm{Co}\left(\mathrm{NO}_{3}\right)_{2} \cdot 6 \mathrm{H}_{2} \mathrm{O}(98.5 \%), \mathrm{SnCl}_{4} \cdot 5 \mathrm{H}_{2} \mathrm{O}(99 \%)$, $\mathrm{In}\left(\mathrm{NO}_{3}\right)_{3}(99 \%), \mathrm{Ga}\left(\mathrm{NO}_{3}\right)_{3} \cdot \mathrm{H}_{2} \mathrm{O}(99 \%)$, thiocarbamide $(98.5 \%)$, starch, gelatin, CA $(98.5 \%)$, glucose $(99 \%)$, sucrose (99\%), lactose (99\%), arabinose (99\%), trehalose (99\%), inulin (99\%), raffinose (99\%), ascorbic acid (99\%), ethylenediaminetetraaceticacid (EDTA, 99\%), acrylamide (99\%), de-ionized water (DW), ethylene glycol (EG), polyvinylpyrrolidone (PVP, K-30), Tween 20, and nitric acid $\left(\mathrm{HNO}_{3}, 65 \%\right)$ were purchased from Sinopharm Chemical Reagent Co., Ltd. Coca-Cola and Sprite were purchased from a grocery store. All the chemicals were used without any purification. In a typical experimental process, $5 \mathrm{~g}$ gelatin was dissolved in $100 \mathrm{~mL}$ DW at $363 \mathrm{~K}$, then $0.7030 \mathrm{~g} \mathrm{H}_{6} \mathrm{TeO}_{6}$ and $1.11 \mathrm{~g}$ PVP were added into the clear solution for preparation of Te NCs. Then the solution was heated at 363-383 K to evaporate the solvent and induce the formation of a polymerized complexing structure. After the solvent was evaporated completely, heat treatment was conducted on the dried polymerized complexing precursor under a $\mathrm{N}_{2}$ protecting atmosphere at different temperatures in a tube furnace. The calcined product was collected and stored in a drying vessel in air without a glove box after room temperature was reached during the cooling procedure. For comparison, gelatin was also replaced by starch to prepare Te NCs. However, $1 \mathrm{~g}$ starch and $200 \mathrm{~mL}$ DW solution were used because of the low solubility of starch in DW, and the masses of $\mathrm{H}_{6} \mathrm{TeO}_{6}$ and PVP were 0.7030 and $1.11 \mathrm{~g}$, respectively. The other procedures were similar to that of the preparation of Te NCs using gelatin. For the preparation of $\mathrm{Ag} \mathrm{NCs}$, an appropriate amount of $\mathrm{AgNO}_{3}$ was used to replace $\mathrm{H}_{6} \mathrm{TeO}_{6}$, and Tween 20 was applied to substitute PVP. For the preparation of $\mathrm{Cu}$ NCs, $\mathrm{H}_{6} \mathrm{TeO}_{6}$ was replaced by $\mathrm{Cu}\left(\mathrm{CH}_{3} \mathrm{COO}\right)_{2} \cdot \mathrm{H}_{2} \mathrm{O}$. For the preparation of Ni NCs, $25 \mathrm{~g} \mathrm{Ni}\left(\mathrm{NO}_{3}\right)_{2} \cdot 6 \mathrm{H}_{2} \mathrm{O}, 50 \mathrm{~g}$ gelatin, and $5.55 \mathrm{~g}$ PVP were dissolved in $100 \mathrm{~mL}$ DW. For the preparation of $\mathrm{Bi} \mathrm{NCs,} \mathrm{Bi}\left(\mathrm{NO}_{3}\right)_{3}$. $5 \mathrm{H}_{2} \mathrm{O}$ and nitric acid were dissolved in DW, and glucose and PVP were used as the bonding agent and surfactant, respectively. In addition, $\mathrm{Bi}\left(\mathrm{NO}_{3}\right)_{3} \cdot 5 \mathrm{H}_{2} \mathrm{O}, \mathrm{CA}$, and PVP were also dissolved in EG to prepare $\mathrm{Bi}$ NCs. For the preparation of bimetallic and semiconductor $\mathrm{NCs}, \mathrm{H}_{6} \mathrm{TeO}_{6}$ was replaced by an appropriate amount of different metallic sources, and DW was substituted by EG for the preparation of $\mathrm{Bi}_{2} \mathrm{Te}_{3}$ and $\mathrm{Sb}_{2} \mathrm{Te}_{3}$ NCs. Detailed experimental conditions for the preparation of different NCs are shown in Table S1 (ESI $\dagger$ ).

X-ray diffraction (XRD, Bruker: D8 Advance) measurements were conducted to analyse the crystalline phases of the as-obtained products with $\mathrm{Cu} \mathrm{K}_{\alpha}$ radiation $(\lambda=0.15406 \mathrm{~nm})$. Transmission electron microscopy (TEM, JEM-2100, $200 \mathrm{kV}$ ) observations were performed to investigate the microstructures of the calcined products. Before TEM observation, the samples were dispersed in ethanol and dropped onto copper grids. The elemental compositions of the calcined products were determined using an energy dispersive spectrometer (EDX, Oxford-2500) attached to a scanning electron microscope (SEM, S-3400). An X-ray fluorescence (XRF, Thermo Fisher ARL Perform) test was also carried out to determine the elemental composition of the BiSb product.

\section{Results and discussion}

Since much attention has been paid to semiconductor NCs because of their potential applications in various fields, we extended the polymerized complexing method from the preparation of metallic NCs to fabricate semiconductor NCs for the first time. Here CdTe, Te, $\mathrm{Ag}_{2} \mathrm{Te}, \mathrm{CuTe}, \mathrm{NiTe}_{1.5}, \mathrm{CoTe}_{1.5}, \mathrm{Bi}_{2} \mathrm{Te}_{3}$, and $\mathrm{Sb}_{2} \mathrm{Te}_{3}$ were selected as typical semiconductors, and NCs of these semiconductors can be successfully obtained by this facile polymerized complexing method. As an example, Fig. 1a-c display the XRD patterns of CdTe NCs formed using $\mathrm{Cd}\left(\mathrm{CH}_{3} \mathrm{COO}\right)_{2} \cdot 3 \mathrm{H}_{2} \mathrm{O}, \mathrm{H}_{6} \mathrm{TeO}_{6}, \mathrm{CA}$, PVP, and DW (a); $\mathrm{H}_{6} \mathrm{TeO}_{6}$, gelatin, Tween 20, and EG (b); and $\mathrm{H}_{6} \mathrm{TeO}_{6}$, gelatin, PVP, and DW (c). In Fig. 1a and b, seven diffraction peaks can be observed, and these diffraction peaks are in agreement with those of face-centered cubic (fcc) CdTe, ${ }^{14}$ and the Miller indices of these peaks are ascribed to (111), (220), (311), (400), (331), (422), and (511), respectively. In Fig. 1c, the main crystalline phase is fcc CdTe, and a secondary phase of Te also appears. The corresponding TEM images of the CdTe NCs in Fig. 1a are 

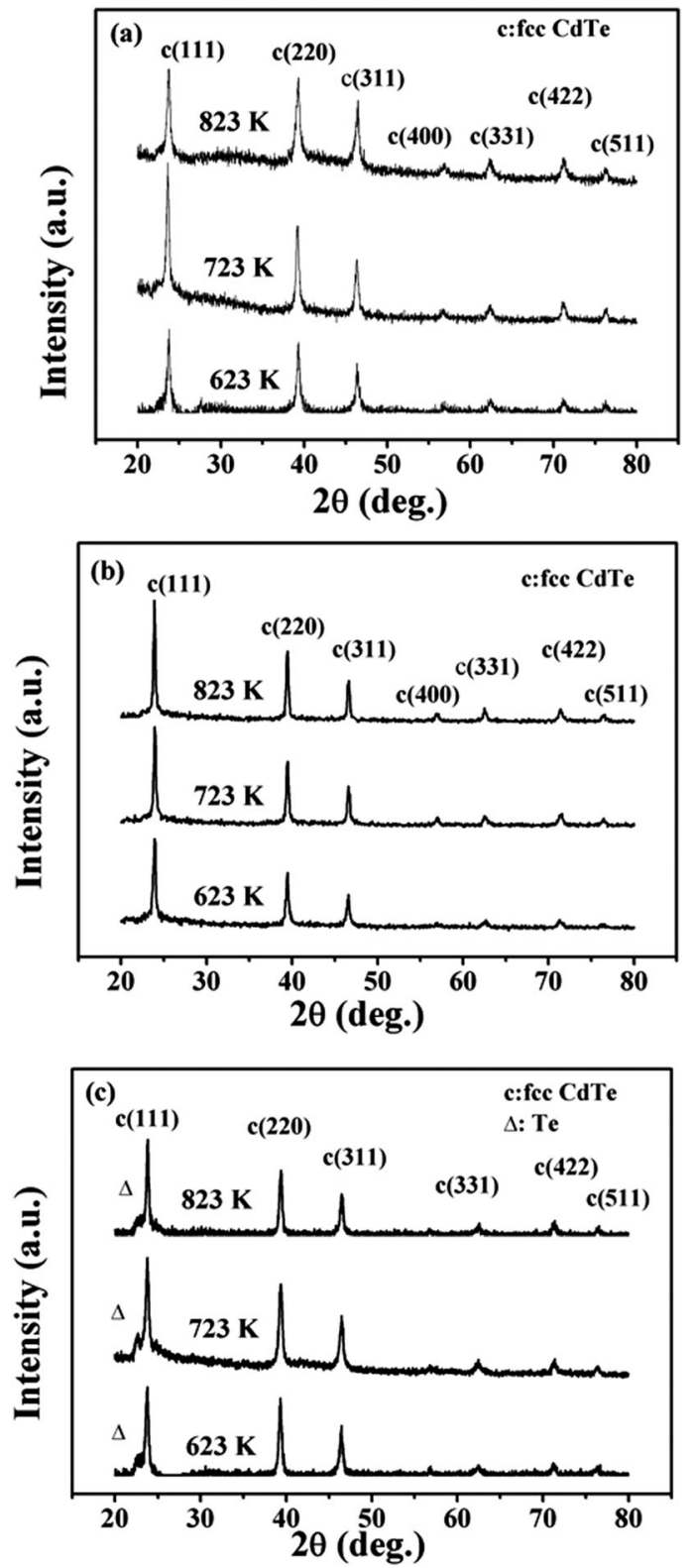

Fig. 1 XRD patterns of the CdTe products calcined at different temperatures employing CA, PVP, and DW (a), gelatin, Tween 20, and EG (b), and gelatin, PVP, and DW (c).

presented in Fig. 2 in which nanograins with sizes of 5-20 nm can be observed when DW is used as the solvent during the synthesis procedure of the CdTe NCs. The selected area electron diffraction (SAED) pattern of the CdTe NCs is shown in Fig. $2 \mathrm{~h}$ where diffraction rings can be observed. According to the radius $\left(R_{1}, R_{2}\right.$, and $\left.R_{3}\right)$ of the three main diffraction rings from the inner to the outer part, the ratio of the square of the radius $\left(R^{2}\right)$ of $R_{1}{ }^{2}: R_{2}{ }^{2}: R_{3}{ }^{2}$ is $3: 8: 11$, showing the fcc crystalline phase of the CdTe NCs, and then the Miller indices of the three diffraction rings are ascribed to (111), (220), and (311), in agreement with the XRD analysis result shown in Fig. 1a. TEM images of CdTe NCs calcined at $723 \mathrm{~K}$ using $\mathrm{H}_{6} \mathrm{TeO}_{6}$, gelatin, Tween 20, and EG are shown in Fig. S1a-c (ESI $\dagger$ ) where grain
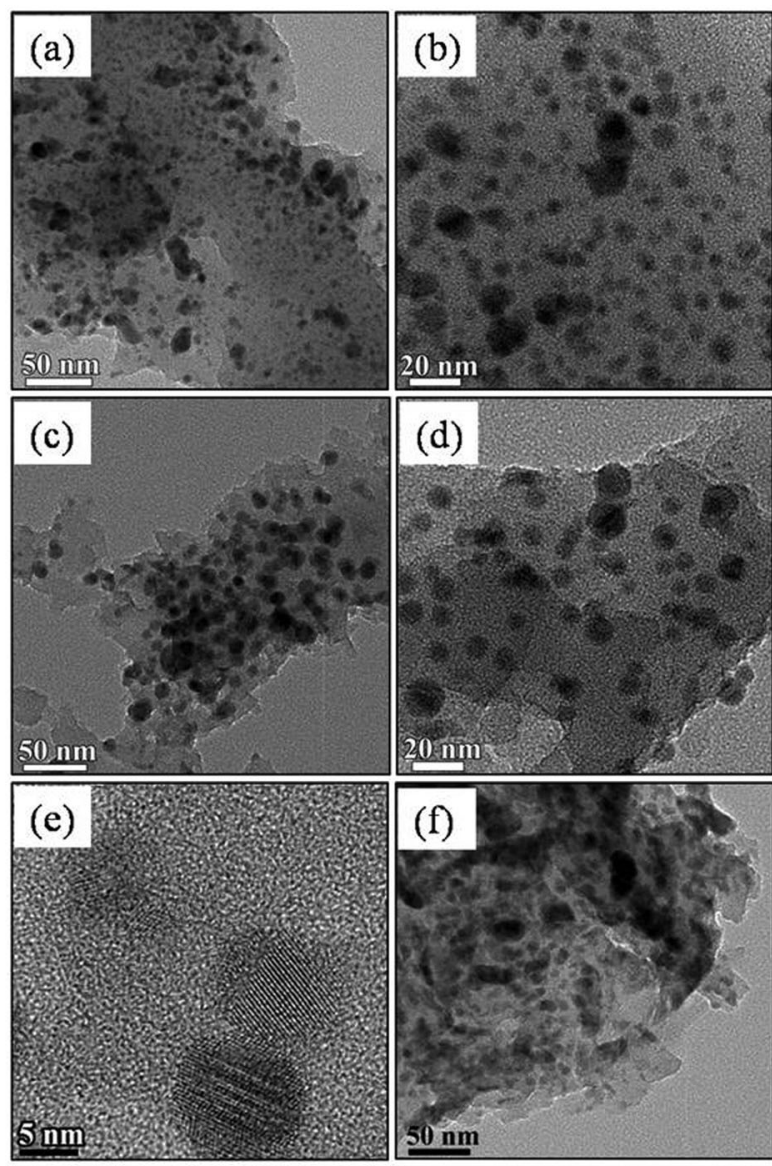

\section{(g)}

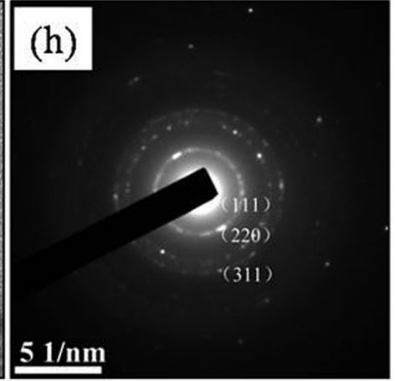

Fig. 2 TEM analysis results of the CdTe NCs calcined at 623 (a and b), 723 $(\mathrm{c}-\mathrm{e})$, and $823(\mathrm{f}-\mathrm{g}) \mathrm{K}$ using $\mathrm{CA}$ as the bonding agent, PVP as the surfactant, and DW as the solvent. SAED pattern of the CdTe NCs calcined at $823 \mathrm{~K}(\mathrm{~h})$.

sizes in the rage of $5-20 \mathrm{~nm}$ can also be observed, and the diffraction rings of the (111), (220), and (311) reflection planes of fcc CdTe NCs can also be observed from the SAED profile (Fig. S1d, ESI $\dagger$ ).

Fig. 3 shows the XRD profiles of Te NCs where the diffraction peaks are in accordance with those of the hexagonal closepacked (hcp) Te crystalline phase (JCPDF: $36-1542) .{ }^{14}$ Fig. 4 displays the TEM images and SAED analysis result of the Te NCs prepared using CA as the bonding agent. Interestingly, the Te NCs show a typical nanorod shape, and the high-resolution transmission electron microscopy (HRTEM) image (Fig. 4d) clearly displays the lattice fringes of the nanorods. Furthermore, Sb (Fig. S2, ESI $\dagger$ ), Bi (Fig. S3 and S4, ESI $\dagger$ ), Bi-Sb (Fig. S5, ESI $\dagger$ ), 

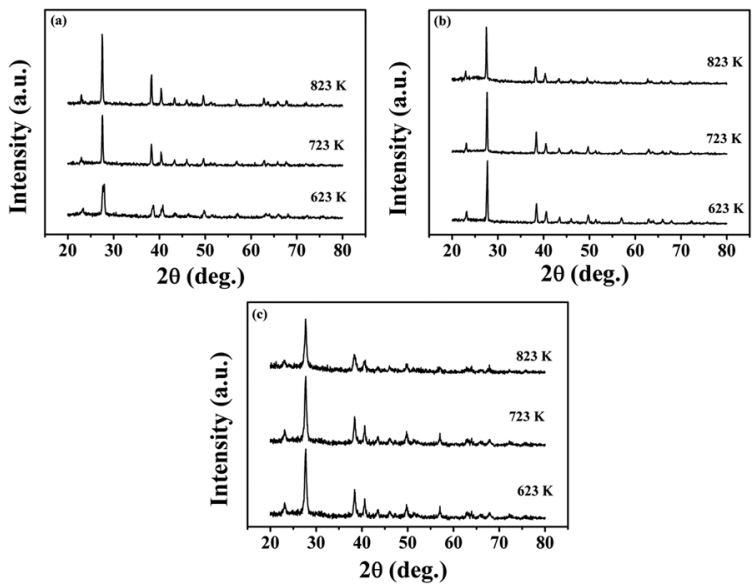

Fig. 3 XRD profiles of the Te products calcined at different temperatures using $\mathrm{H}_{6} \mathrm{TeO}_{6}$, PVP, DW, and CA (a), gelatin (b), and starch (c), respectively.
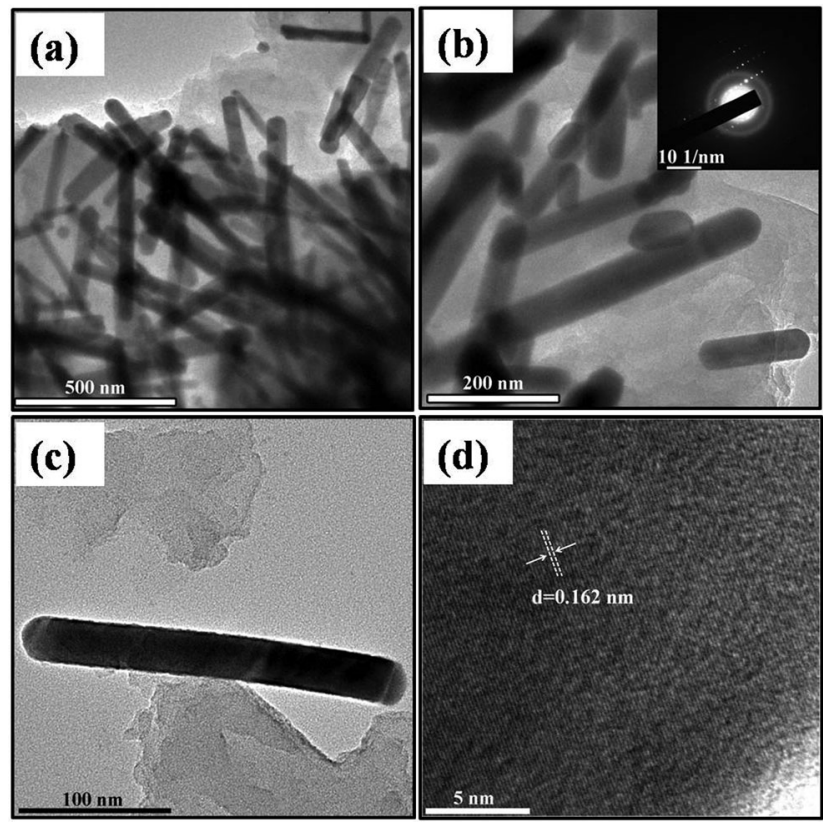

Fig. 4 TEM images and SAED analysis result of the Te NCs calcined at $623 \mathrm{~K}$ using CA as the bonding agent, PVP as the surfactant, and DW as the solvent.

$\mathrm{Ag}_{2} \mathrm{Te}$, CuTe, $\mathrm{NiTe}_{1.5}, \mathrm{CoTe}_{1.5}, \mathrm{Bi}_{2} \mathrm{Te}_{3}$, and $\mathrm{Sb}_{2} \mathrm{Te}_{3}$ (Fig. S6-S11, $\mathrm{ESI} \dagger)$ NCs can also be prepared by this polymerized complexing method. The crystalline phases of the as-prepared $\mathrm{Ag}_{2} \mathrm{Te}, \mathrm{NiTe}_{1.5}$, $\mathrm{Bi}_{2} \mathrm{Te}_{3}$, and $\mathrm{Sb}_{2} \mathrm{Te}_{3} \mathrm{NCs}$ are monoclinic (JCPDF: 65-1104), hexagonal (JCPDF: 65-3377), rhombohedral (JCPDF: 15-0863), ${ }^{20}$ and rhombohedral (JCPDF: 15-0874), ${ }^{21}$ respectively. The diffraction peaks in Fig. S6b (ESI $\dagger$ ) for the CuTe NCs prepared by this method are in accordance with those of $\mathrm{Cu}_{0.57} \mathrm{Te}_{0.43}$ (JCPDF: 37-1028).

For $\mathrm{Ag}_{2} \mathrm{Te} \mathrm{NCs}$, gelatin can be used as the bonding agent. However, CA is not effective in the preparation of $\mathrm{Ag}_{2} \mathrm{Te}$ NCs. The reason why is that CA can reduce $\mathrm{Ag}^{+}$ions directly into $\mathrm{Ag}$ precipitate in aqueous solution, and then the $\mathrm{Ag}_{2}$ Te crystalline phase can not be obtained. Therefore, the first requirement of a bonding agent is a low reducing ability in solution. Interestingly, for the CuTe system, CA is effective in the formation of CuTe NCs and gelatin is not effective, and precipitation can be observed in aqueous solution when gelatin is used. This result originates from the fact that the value of $C_{\left(\mathrm{Cu}^{2+}\right)} \cdot C_{\left(\mathrm{Te}^{2-}\right)}$ is higher than the solubility product constant $\left(K_{\mathrm{sp}}\right)$ of CuTe when gelatin is applied, where $C$ denotes the concentration of free ions. In aqueous solution, the metallic ions are bonded with the bonding agent, resulting in low concentrations of the free metallic ions. However, due to the different bonding ability of CA and gelatin, the concentrations of free ions are different. As a result, the formation of CuTe NCs using CA and gelatin is quite different. This implies that the second requirement of a bonding agent is a strong bonding ability with metallic ions in solution. The total effect of the bonding agent is to form chemical bonds with metallic ions to reduce the concentrations of free metallic ions and to prevent the occurrence of precipitation.

In addition, metallic Ag (Fig. S12, ESI $\dagger$ ), $\mathrm{Cu}$ (Fig. S13a, ESI $\dagger$ ), and Ni (Fig. S13b and S14, ESI $\dagger$ ) NCs can also be obtained by employing gelatin as the bonding agent, and $4.8 \mathrm{~g}$ Ni NCs can be obtained from one single batch experiment (Fig. S14, ESI $\dagger$ ). Cobalt NCs with a fcc crystalline phase can also be obtained when the heating temperatures are higher than $873 \mathrm{~K}$, and oxide peaks can be observed when the heating temperatures are lower than $873 \mathrm{~K}$ (Fig. S15, ESI $\dagger$ ). For the preparation of $\mathrm{Cd}$ metallic powders, the only successful result is obtained when using glucose as the bonding agent (Fig. S16, ESI $\dagger$ ). When the heating temperatures are 623 and $723 \mathrm{~K}$, the preparation of Sn NCs is not successful by employing glucose as the bonding agent, and only the $\mathrm{SnO}_{2}$ crystalline phase can be observed (Fig. S17, ESI $\dagger$ ). However, both $\mathrm{Sn}$ and $\mathrm{SnO}_{2}$ phases can be detected by XRD when the heating temperature is $823 \mathrm{~K}$ (Fig. S17, ESI $\dagger$ ). This means that $\mathrm{SnO}_{2}$ NCs first appear during heat treatment under the protecting $\mathrm{N}_{2}$ atmosphere, and then $\mathrm{SnO}_{2}$ NCs transform to Sn NCs. However, this transformation is not completed at $823 \mathrm{~K}$. When the heating temperature is $1173 \mathrm{~K}$, only the diffraction peaks of $\mathrm{Sn}$ with a tetragonal crystalline phase can be observed (Fig. S17, ESI, $\dagger$ JCPDF: 04-0673), indicating that $\mathrm{SnO}_{2}$ transforms completely to $\mathrm{Sn}$ at this temperature.

These results show that typical semiconductor NCs of CdTe, $\mathrm{Bi}-\mathrm{Sb}, \mathrm{NiTe}_{1.5}, \mathrm{CuTe}, \mathrm{Ag}_{2} \mathrm{Te}, \mathrm{Bi}_{2} \mathrm{Te}_{3}$, and $\mathrm{Sb}_{2} \mathrm{Te}_{3}$ as well as elemental Te semiconductor NCs can be prepared by this polymerized complexing method besides typical metallic $\mathrm{Bi}, \mathrm{Sb}, \mathrm{Ag}, \mathrm{Cu}, \mathrm{Ni}$, and Co NCs. In order to explain the reason why these semiconductor and metallic crystalline phases can be obtained by this environmentally friendly method, the intrinsic principle of this method is explored. In general, the formation of a metallic crystalline phase is a reducing process, and then factors that can affect the redox reaction should be considered. Firstly, electronegativity is a widely accepted parameter which reflects the ability of an atom to attract electrons, ${ }^{22}$ and a conventional scale of electronegativity has been proposed by Pauling based on the calculation of bond energies. ${ }^{18}$ This parameter can be applied to explain the experimental results of the nanocrystalline inter-metallics and alloys formed by two metallic elements in an octadecylamine solution-based synthesis system where 
the electronegativity should be higher than a critical value. ${ }^{23,24}$ It is then assumed that there may be a critical value of electronegativity in our experimental results. However, this critical value does not apply to our experiments. The electronegativities of $\mathrm{Cd}, \mathrm{Co}, \mathrm{Cu}, \mathrm{Ni}, \mathrm{Ag}, \mathrm{Bi}, \mathrm{Sb}, \mathrm{Te}, \mathrm{Pd}, \mathrm{Pt}$, and $\mathrm{Sn}$ are 1.69, 1.88, 1.90, 1.91, 1.93, 2.02, 2.05, 2.10, 2.20, 2.28, and 1.96 (Table S2, ESI $\dagger$ ), respectively. The electronegativity of $\mathrm{Cd}$ (1.69) is lower than that of Sn (1.96). However, a Cd crystalline phase can be obtained while Sn NCs can not be prepared in the range of 623-823 K. Using another scale of electronegativity such as the table of Allred-Rochow (Table S3, ESI $\dagger$ ), the corresponding value of $\mathrm{Cd}$ (1.46) is also lower than that of $\mathrm{Sn}$ (1.72), and the electronegativity of $\mathrm{Ni}(1.75)$ is very close to that of Sn. Therefore, the electronegativity rule can not be applied in this polymerized complexing method.

The second parameter is based on quantitative calculation of the change of Gibbs free energy $\left(\Delta_{\mathrm{f}} G_{\mathrm{m}}^{\varnothing}\right)$ of a chemical reaction. The third parameter is the calculation of the electromotive force $\left(E^{0}\right)$ of a reaction. These two parameters are intrinsically the same according to the Nernst equation:

$$
\Delta_{\mathrm{f}} G_{\mathrm{m}}^{\varnothing}=-Z F E^{0}
$$

and

$$
E^{0}=E^{+} \text {(right half cell) }-E^{-} \text {(left half cell) }
$$

where $Z$ is the number of electrons in the reaction, $F$ is the Faraday constant $\left(F=96485 \mathrm{C} \mathrm{mol}^{-1}\right),{ }^{17}$ and $E^{+}$and $E^{-}$are the electrode potentials of the two half reactions. ${ }^{17}$ If $\Delta_{\mathrm{f}} G_{\mathrm{m}}^{\varnothing}<0$ and $E^{0}>0$, then the reaction can occur spontaneously. If $\Delta_{\mathrm{f}} G_{\mathrm{m}}^{\varnothing}>0$ and $E^{0}<0$, then the inverse reaction can take place spontaneously. The metal redox standard electrode potentials $\left(\mathrm{M}^{n+}+n \mathrm{e}^{-} \rightarrow \mathrm{M}\right)$ at room temperature may be the second factor controlling the formation of the metallic crystalline phase in this method. Based on the list of metal redox standard electrode potentials at room temperature (Table S4, ESI $\dagger$ ), the metal redox standard electrode potentials of $\mathrm{Cd}^{2+}, \mathrm{Co}^{2+}, \mathrm{Ni}^{2+}$, $\mathrm{Sn}^{4+}, \mathrm{SbO}^{+}, \mathrm{Bi}^{3+}, \mathrm{Cu}^{2+}, \mathrm{Ag}^{+}, \mathrm{Pd}^{2+}$, and $\mathrm{Pt}^{4+}$ ions are -0.403 , $-0.282,-0.257,0.008,0.204,0.317,0.340,0.7991,0.951$, and $1.118 \mathrm{~V}$, respectively. The standard electrode potential of $\mathrm{Cd}^{2+}$ is the lowest and that of $\mathrm{Sn}^{4+}$ is in the middle part of these values. Therefore, the electrode potential of the half reaction of $\mathrm{M}^{n+}+n \mathrm{e}^{-} \rightarrow \mathrm{M}$ can also not be the main controlling factor for the preparation of metallic NCs in this method.

It is noted that heat treatment is carried out in the experiments, and so high temperature parameters should be considered. Since the high temperature values of electrode potentials are not available, we resort to the calculation of $\Delta_{\mathrm{f}} G_{\mathrm{m}}^{\varnothing}$ as a function of temperature, and the corresponding calculation results match well with the experimental data. It is worth noting that reducing gases such as $\mathrm{H}_{2}$ and $\mathrm{CH}_{4}$ are released during the heat treatment procedure as confirmed by mass spectroscopy. ${ }^{19}$ The formation mechanism is inferred that oxide crystalline nuclei are formed during the calcination procedure under a $\mathrm{N}_{2}$ protecting atmosphere, then the oxide nuclei are reduced to metallic or semiconductor NCs by reducing gases, which was confirmed by the XRD analysis results of Co and Sn, where oxide phases occur at certain temperatures and then metallic phases appear at higher temperatures. The reaction path for the formation of element NCs can therefore be depicted as:

$$
\mathrm{MO}_{x}+x \mathrm{H}_{2} \rightarrow \mathrm{M}+x \mathrm{H}_{2} \mathrm{O}(\mathrm{g})
$$

where $\mathbf{M}$ represents a metallic element. By calculating the standard enthalpy change $\left(\Delta_{\mathrm{f}} H_{\mathrm{m}}^{\varnothing}\right)$ and standard entropy change $\left(\Delta_{\mathrm{f}} S_{\mathrm{m}}^{\varnothing}\right)$, the relation between $\Delta_{\mathrm{f}} G_{\mathrm{m}}^{\varnothing}$ and the temperature (K) of reaction (3) is expressed as:

$$
\Delta_{\mathrm{f}} G_{\mathrm{m}}^{\varnothing}=\Delta_{\mathrm{f}} H_{\mathrm{m}}^{\varnothing}-T \times \Delta_{\mathrm{f}} S_{\mathrm{m}}^{\varnothing}
$$

where

$$
\Delta_{\mathrm{f}} H_{\mathrm{m}}^{\varnothing}=\sum_{i} \nu_{\mathrm{B}} \Delta_{\mathrm{f}} H_{\mathrm{m}}^{\varnothing} \quad \text { and } \quad \Delta_{\mathrm{f}} S_{\mathrm{m}}^{\varnothing}=\sum_{i} \nu_{\mathrm{B}} S_{\mathrm{m}}^{\varnothing} .
$$

In eqn (5), $\nu_{\mathrm{B}}$ is the reaction coefficient (positive for reaction products on the right side of reaction (3) and negative for initial reaction substances on the left side of reaction (3)) and $S_{\mathrm{m}}^{\varnothing}$ is standard entropy. $\Delta_{\mathrm{f}} G_{\mathrm{m}}^{\varnothing}$ can then be calculated from data in the thermodynamical handbook. ${ }^{25}$ For instance, $\Delta_{\mathrm{f}} H_{\mathrm{m}}^{\varnothing}$ and $\Delta_{\mathrm{f}} S_{\mathrm{m}}^{\varnothing}$ of the reaction of

$$
\mathrm{TeO}_{2}+2 \mathrm{H}_{2} \rightarrow \mathrm{Te}+2 \mathrm{H}_{2} \mathrm{O}(\mathrm{g})
$$

are expressed as:

$$
\begin{aligned}
\Delta_{\mathrm{f}} H_{\mathrm{m}}^{\varnothing}(\text { reaction })= & \Delta H_{\mathrm{m}}^{\varnothing}(\mathrm{Te})+2 \Delta H_{\mathrm{m}}^{\varnothing}\left(\mathrm{H}_{2} \mathrm{O}(\mathrm{g})\right)-\Delta H_{\mathrm{m}}^{\varnothing}\left(\mathrm{TeO}_{2}\right) \\
& -2 \Delta H_{\mathrm{m}}^{\varnothing}\left(\mathrm{H}_{2}\right)
\end{aligned}
$$

and

$$
\begin{aligned}
\Delta_{\mathrm{f}} S_{\mathrm{m}}^{\varnothing}(\text { reaction })= & S_{\mathrm{m}}^{\varnothing}(\mathrm{Te})+2 S_{\mathrm{m}}^{\varnothing}\left(\mathrm{H}_{2} \mathrm{O}(\mathrm{g})\right)-S_{\mathrm{m}}^{\varnothing}\left(\mathrm{TeO}_{2}\right) \\
& -2 S_{\mathrm{m}}^{\varnothing}\left(\mathrm{H}_{2}\right)
\end{aligned}
$$

as an approximation, $\Delta_{\mathrm{f}} H_{\mathrm{m}}^{\varnothing}$ and $\Delta_{\mathrm{f}} S_{\mathrm{m}}^{\varnothing}$ are considered to be constant. $\Delta_{\mathrm{f}} G_{\mathrm{m}}^{\varnothing}<0$ is also the criterion for the spontaneous occurrence of reaction (6). Thermodynamical data ${ }^{25}$ of $\Delta_{\mathrm{f}} H_{\mathrm{m}}^{\varnothing}$ and $S_{\mathrm{m}}^{\varnothing}$ of pure substances are shown in Table S5 (ESI $\dagger$ ), and $\Delta_{\mathrm{f}} H_{\mathrm{m}}^{\varnothing}$ and $\Delta_{\mathrm{f}} S_{\mathrm{m}}^{\varnothing}$ of reaction (6) are calculated to be $-186.839 \mathrm{~kJ} \mathrm{~mol}^{-1}$ and $74.557 \mathrm{~J} \mathrm{~mol}^{-1} \mathrm{~K}^{-1}$, and $\Delta_{\mathrm{f}} G_{\mathrm{m}}^{\varnothing}$ at room temperature $(298.15 \mathrm{~K})$ is determined to be $-209.07 \mathrm{~kJ} \mathrm{~mol}^{-1}$. The same calculations can be performed on other reactions and the corresponding results are displayed in Fig. 5 where metallic elements can be divided into three types.

The type 1 elements are determined by $\Delta_{\mathrm{f}} H_{\mathrm{m}}^{\varnothing}<0$ and $\Delta_{\mathrm{f}} S_{\mathrm{m}}^{\varnothing}>0$, and then $\Delta_{\mathrm{f}} G_{\mathrm{m}}^{\varnothing}<0$ occurs at any temperature. As a result, a metallic phase can be obtained during the calcination procedure when the polymerized structure decomposes at a certain temperature. This first type of metallic element includes $\mathrm{Ni}, \mathrm{Cu}, \mathrm{Sb}, \mathrm{Pd}, \mathrm{Bi}$, Te, As, Hg, Ru, Ir, Se, Rh, Os, and Au, as shown in Fig. $5 \mathrm{a}$ and b. In the case of Co, $\Delta_{\mathrm{f}} H_{\mathrm{m}}^{\varnothing}<0$ and $\Delta_{\mathrm{f}} S_{\mathrm{m}}^{\varnothing}>0$ if the cobalt oxide is $\mathrm{Co}_{3} \mathrm{O}_{4}$. But $\Delta_{\mathrm{f}} H_{\mathrm{m}}^{\varnothing}>0$ and $\Delta_{\mathrm{f}} S_{\mathrm{m}}^{\varnothing}>0$ if the cobalt oxide is $\mathrm{CoO}$, and then high temperature is required to make $\Delta_{\mathrm{f}} G_{\mathrm{m}}^{\varnothing}<0$. Combined this calculation result with the experimental result of Fig. S15 (ESI $\dagger$ ), where the heating temperature needs to be higher than $873 \mathrm{~K}$ to induce the transformation from any cobalt oxide phase to the fcc Co metallic phase, then Co is also catalogued as a type 1 element. 

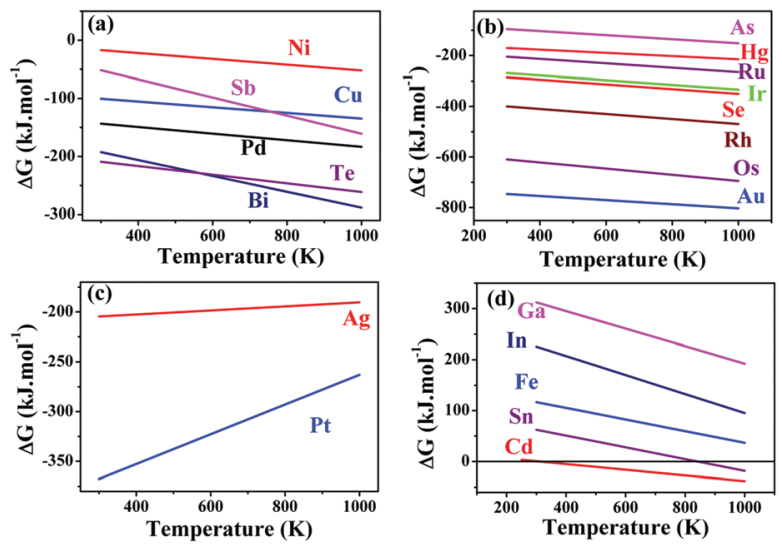

Fig. 5 Thermodynamical calculation results of $\Delta_{f} G_{m}^{\varnothing}$ of reaction (3) of metallic elements.

The type 2 elements are defined when $\Delta_{\mathrm{f}} H_{\mathrm{m}}^{\varnothing}<0$ and $\Delta_{\mathrm{f}} S_{\mathrm{m}}^{\varnothing}<0$, and the heating temperature should be lower than an upper critical temperature to ensure that $\Delta_{\mathrm{f}} G_{\mathrm{m}}^{\varnothing}<0$. This second type includes Ag and Pt (Fig. 5c), and the upper critical temperatures calculated according to eqn (7)

$$
T_{\mathrm{c}}=\frac{\Delta_{\mathrm{f}} H_{\mathrm{m}}^{\varnothing}}{\Delta_{\mathrm{f}} S_{\mathrm{m}}^{\varnothing}}
$$

for Ag and Pt are 10361 and $2757 \mathrm{~K}$, respectively. The heating temperatures in our experiments (623-823 K) are much lower than these two critical temperatures, indicating that $\mathrm{Ag}$ and Pt NCs can also be prepared by this environmentally friendly method.

The type 3 elements are defined when $\Delta_{\mathrm{f}} H_{\mathrm{m}}^{\varnothing}>0$ and $\Delta_{\mathrm{f}} S_{\mathrm{m}}^{\varnothing}>0$, and the heating temperature should be higher than a lower critical temperature so that $\Delta_{\mathrm{f}} G_{\mathrm{m}}^{\varnothing}<0$, and the calculation formula of this critical temperature is the same as eqn (7). All the other metallic elements are included in this type. Typical examples are In and Ga (Fig. 5d) where the lower critical temperatures are 1512 and $2120 \mathrm{~K}$, which are much higher than the experimental range (623-823 K). Oxide NCs of these elements can be obtained more easily although the heat treatments are performed under a $\mathrm{N}_{2}$ protecting atmosphere. One exception is Cd because its critical temperature is calculated to be $310 \mathrm{~K}$ (Fig. 5d), which lies in the experimental temperature range. However, the experimental preparation of Cd NCs is much more difficult than the fabrication of NCs of type 1 and 2 elements since only one successful result has been obtained for $\mathrm{Cd}$ at present. The calculation results of Sn show that the critical temperature is about $842 \mathrm{~K}$, indicating that the reduction reaction should not take place at temperatures lower than $842 \mathrm{~K}$, and then the oxide crystalline phase instead of the metallic phase should be obtained. This is in agreement with the XRD results of Sn (Fig. S17, ESI $\dagger$ ) where the $\mathrm{SnO}_{2}$ phase was detected at 623 and $723 \mathrm{~K}$ and the coexistence of $\mathrm{SnO}_{2}$ and $\mathrm{Sn}$ can be observed at $823 \mathrm{~K} . \Delta_{\mathrm{f}} G_{\mathrm{m}}^{\varnothing}$ is calculated to be negative when the temperature is higher than $842 \mathrm{~K}$, and this is also confirmed by the experimental result where a pure Sn tetragonal phase can be detected by XRD when the heat treatment is operated at $1173 \mathrm{~K}$ (Fig. S17, ESI $\dagger$ ).
For the preparation of alloys or compounds consisting of two kinds of element, the reaction path can be expressed as:

$$
\mathrm{aAO}_{x}+\mathrm{bBO}_{y}+(\mathrm{a} x+\mathrm{b} y) \mathrm{H}_{2} \rightarrow \mathrm{A}_{\mathrm{a}} \mathrm{B}_{\mathrm{b}}+(\mathrm{a} x+\mathrm{b} y) \mathrm{H}_{2} \mathrm{O}(\mathrm{g})
$$

where A and B denote different metallic elements. It is expected that those alloys and compounds consisting of type 1 and 2 elements can be prepared by this method. A typical example is $\mathrm{Bi}-\mathrm{Sb}$ solid solution NCs with various atomic ratios of $\mathrm{Bi}: \mathrm{Sb}$ (Fig. S5, ESI $\dagger$ ). Fig. 6a displays the thermodynamical calculation results of typical compounds of $\mathrm{NiTe}_{1.1}, \mathrm{CuTe}, \mathrm{Ag}_{2} \mathrm{Te}, \mathrm{Bi}_{2} \mathrm{Te}_{3}$, and $\mathrm{Sb}_{2} \mathrm{Te}_{3}$, consisting of type 1 and 2 elements. It can be seen from Fig. 6a that all the calculated $\Delta_{\mathrm{f}} G_{\mathrm{m}}^{\varnothing}$ values are lower than 0 , and $\Delta_{\mathrm{f}} H_{\mathrm{m}}^{\varnothing}<0$ and $\Delta_{\mathrm{f}} S_{\mathrm{m}}^{\varnothing}>0$. Therefore, these compounds are predicted to be formed spontaneously during the heat treatment procedure, and this prediction is verified by the corresponding XRD profiles and TEM images in Fig. S6-S10 (ESI†).

For the compounds consisting of type 3 elements and those of type 1 and 2 elements, it is expected that the compounds may be prepared if the calculated $\Delta_{\mathrm{f}} G_{\mathrm{m}}^{\varnothing}$ value of reaction (8) is lower than $0 . \mathrm{Ni}_{3} \mathrm{Sn},{ }^{26} \mathrm{CdTe}, \mathrm{In}_{2} \mathrm{Te}_{3}$, and $\mathrm{SnTe}$ are selected as this type of compound to verify this prediction. Fig. $6 \mathrm{~b}$ and $\mathrm{c}$ show the calculated results of these compounds, where all the $\Delta_{\mathrm{f}} G_{\mathrm{m}}^{\varnothing}$ values are negative, $\Delta_{\mathrm{f}} H_{\mathrm{m}}^{\varnothing}$ is negative, and $\Delta_{\mathrm{f}} S_{\mathrm{m}}^{\varnothing}$ is positive. Interestingly, the $\mathrm{In}_{2} \mathrm{Te}_{3}$, SnSb, and SnTe products with a fcc crystalline phase can also be obtained when the heating temperature is $723 \mathrm{~K}$ (Fig. S18, ESI $\dagger$ ), and peaks indicating purity appear at both 623 and $823 \mathrm{~K}$. These results mean that the combination of elements of type 1 and 2 with type 3 elements can be used to prepare the corresponding compounds although the type 3 metallic elements are very difficult to obtain. Furthermore, ternary compounds of $\mathrm{Ni}_{2.9} \mathrm{SnTe}_{2}, \mathrm{CuGaTe}_{2}$, and $\mathrm{CuInS}_{2}$ can also be obtained by this method (Fig. S19, ESI $\dagger$ ) when the heating temperature is $723 \mathrm{~K}$.

Since the thermodynamical calculation results are in excellent agreement with experimental data, the calculation of $\Delta_{\mathrm{f}} G_{\mathrm{m}}^{\varnothing}$ of the reaction paths can be regarded as the intrinsic thermodynamical criterion for this polymerized complexing method, and the controlling factor for the formation of metallic and semiconductor
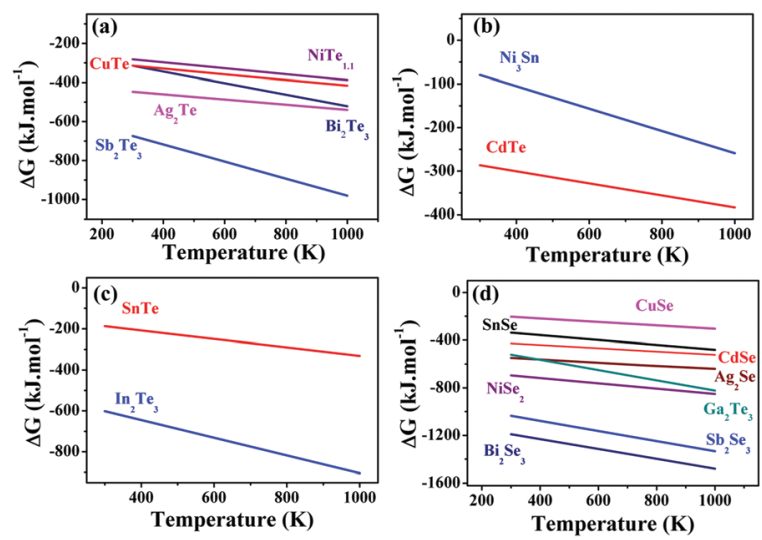

Fig. 6 Thermodynamical calculation results of $\Delta_{\mathrm{f}} G_{\mathrm{m}}^{\varnothing}$ of reaction (8) of compounds consisting of two metallic elements or metallic and semimetallic elements. 
NCs is the reduction reaction of oxide by reducing gases during the heat treatment, not the electronegativities of the elements or the metal redox standard electrode potentials. Based on the calculation results of Fig. 5 and $6, \Delta_{\mathrm{f}} G_{\mathrm{m}}^{\varnothing}$ is mainly determined by $\Delta_{\mathrm{f}} H_{\mathrm{m}}^{\varnothing}$. If $\Delta_{\mathrm{f}} H_{\mathrm{m}}^{\varnothing}<0$, then $\Delta_{\mathrm{f}} G_{\mathrm{m}}^{\varnothing}$ is negative in the experimental temperature range $(623-823 \mathrm{~K})$, and $\Delta_{\mathrm{f}} G_{\mathrm{m}}^{\varnothing}>0$ occurs when $\Delta_{\mathrm{f}} H_{\mathrm{m}}^{\varnothing}>0$ with only one exception of $\mathrm{Cd}$. Therefore, the values of $\Delta_{\mathrm{f}} H_{\mathrm{m}}^{\varnothing}$ and $\Delta_{\mathrm{f}} G_{\mathrm{m}}^{\varnothing}$ of the reduction reaction of oxide at room temperature $(298.15 \mathrm{~K})$ are the main parameters that determine the reaction direction and formation of the crystalline phase. According to eqn (1), $\Delta_{\mathrm{f}} G_{\mathrm{m}}^{\varnothing}$ at room temperature is proportional to the electromotive force $\left(E^{0}\right)$ of the reduction reaction of oxide at room temperature, and so $E^{0}$ is also the main parameter. For instance, the half reactions of $\mathrm{TeO}_{2}+2 \mathrm{H}_{2} \rightarrow \mathrm{Te}+2 \mathrm{H}_{2} \mathrm{O}(\mathrm{l})$ are:

$$
E^{+}: \mathrm{TeO}_{2}+4 \mathrm{H}^{+}+4 \mathrm{e}^{-} \rightarrow \mathrm{Te}+2 \mathrm{H}_{2} \mathrm{O}(\mathrm{l})
$$

and

$$
\begin{gathered}
E^{-}: 2 \mathrm{H}_{2}+4 \mathrm{e}^{-} \rightarrow 4 \mathrm{H}^{+} \\
E^{0}=E^{+}-E^{-}
\end{gathered}
$$

where $\mathrm{H}_{2} \mathrm{O}(\mathrm{l})$ is the stable phase of $\mathrm{H}_{2} \mathrm{O}$ at room temperature since electrode potentials are often measured at room temperature. In eqn (9)-(11), $E^{+}$is $0.53 \mathrm{~V}$ at room temperature, ${ }^{27}$ and $E^{-}$is the standard hydrogen electrode potential, which is $0 \mathrm{~V}$. Therefore $E^{0}$ is $0.53 \mathrm{~V}$, and $\Delta_{\mathrm{f}} G_{\mathrm{m}}^{\varnothing}$ at $298.15 \mathrm{~K}$ is calculated to be: $\Delta_{\mathrm{f}} G_{\mathrm{m}}^{\varnothing}=-Z F E^{0}=-4 \times 96485 \mathrm{C} \mathrm{mol}^{-1} \times 0.53 \mathrm{~V}=-204.55 \mathrm{~kJ} \mathrm{~mol}^{-1}$, in agreement with the value of $\Delta_{\mathrm{f}} G_{\mathrm{m}}^{\varnothing}$ at $298.15 \mathrm{~K}\left(-209.07 \mathrm{~kJ} \mathrm{~mol}^{-1}\right)$ calculated from $\Delta_{\mathrm{f}} H_{\mathrm{m}}^{\varnothing}$ and $\Delta_{\mathrm{f}} S_{\mathrm{m}}^{\varnothing}$. If $\mathrm{H}_{2} \mathrm{O}(\mathrm{g})$ is substituted by $\mathrm{H}_{2} \mathrm{O}(\mathrm{l})$ in calculating $\Delta_{\mathrm{f}} G_{\mathrm{m}}^{\varnothing}$ of reaction (6) from enthalpy and entropy, the corresponding result of $\Delta_{\mathrm{f}} G_{\mathrm{m}}^{\varnothing}$ is $-199.50 \mathrm{~kJ} \mathrm{~mol}^{-1}$, also in agreement with the $\Delta_{\mathrm{f}} G_{\mathrm{m}}^{\varnothing}$ value determined from $E^{0}$. For other reduction reactions of oxides, i.e.

$$
\begin{gathered}
E^{+}: \mathrm{MO}_{x}+2 x \mathrm{H}^{+}+2 x \mathrm{e}^{-} \rightarrow \mathrm{M}+x \mathrm{H}_{2} \mathrm{O}(\mathrm{l}) \\
E^{-}: 2 \mathrm{H}^{+}+2 \mathrm{e}^{-} \rightarrow \mathrm{H}_{2}
\end{gathered}
$$

$E^{0}=E^{+}-E^{-}=E^{+}$, then $E^{+}>0$ can also be the criterion for this polymerized complexing method with $E^{+}$being the metal oxide redox standard electrode potential. Unfortunately, only $E^{+}$of the half reaction of the reduction of $\mathrm{TeO}_{2}$ oxide can be retrieved, ${ }^{27}$ and so calculation of $\Delta_{\mathrm{f}} G_{\mathrm{m}}^{\varnothing}$ from enthalpy and entropy is much more convenient. The half reaction of the reduction of oxide is quite different from those of the reduction of metallic ions, as shown in the difference between the half reactions of:

$$
\mathrm{NiO}+2 \mathrm{H}^{+}+2 \mathrm{e}^{-} \rightarrow \mathrm{Ni}+\mathrm{H}_{2} \mathrm{O}(\mathrm{l})
$$

and

$$
\mathrm{Ni}^{2+}+2 \mathrm{e}^{-} \rightarrow \mathrm{Ni}
$$

where reaction (13) represents the half reaction of the reduction of $\mathrm{NiO}$ and reaction (14) denotes the half reaction of the reduction of $\mathrm{Ni}^{2+}$ with a standard metal redox electrode potential of $-0.257 \mathrm{~V}$. This is the reason why metal redox potentials (Table S4, ESI $\dagger$ ) can not be used in the reasoning for this polymerized complexing method. In addition, the controlling reaction is the reduction of oxide, and then transfer of electrons takes place between the oxide phase and reducing gases, thus using the electronegativity of elements to predict the reaction rule is also not appropriate for this method. However, it is worth noting that standard metal redox electrode potentials still serve an important role in determining the occurrence of polymerized complexing between the bonding agent and metallic ions or the reduction of metallic ions by a bonding agent in aqueous solution. In our previous work, $\mathrm{Ag}^{+}$ions could be reduced directly by glucose and CA in aqueous solution, ${ }^{19}$ and it is difficult to control the reducing rate. $\mathrm{Ni}^{2+}$ ions can bond with glucose and CA in aqueous solution and then form a polymerized complexing structure during the drying procedure. This difference originates from the different standard electrode potentials of $\mathrm{Ag}^{+}(0.7991 \mathrm{~V})$ and $\mathrm{Ni}^{2+}(-0.257 \mathrm{~V})$. If the electrode potential of the bonding agent is lower than that of $\mathrm{Ag}^{+}$but higher than that of $\mathrm{Ni}^{2+}$, then $\mathrm{Ag}^{+}$can be reduced in aqueous solution directly while $\mathrm{Ni}^{2+}$ ions can not be reduced by the bonding agent. On the contrary, coordinate bonds form between the $\mathrm{Ni}^{2+}$ ions and the bonding agent, and it is the metal oxide redox electrode potential of $\mathrm{NiO}$ that should be responsible for the occurrence of the Ni crystalline phase in the final calcined product. Therefore, the metal redox standard electrode potential is the controlling factor in determining the occurrence of polymerized complexing or the reduction of ions directly in aqueous solution, and the metal oxide redox standard electrode potential is the main factor controlling the crystalline phase of the NCs prepared by heat treatment under a $\mathrm{N}_{2}$ protecting atmosphere. In addition, it should be pointed out that metal and metal oxide NCs do not form during the evaporation of solvents and the formation procedure of the polymerized complex, as evidenced by the lack of diffraction peaks observed even when the temperature reached $573 \mathrm{~K}$; only diffraction peaks of Ni NCs can be detected when heating at high temperatures in the range of 623-1073 K (Fig. S13 and S20, ESI $\dagger$ ).

Based on the above discussion, the basic principles of this polymerized complexing method and conventional reduction methods are displayed in Fig. 7. In general, metallic ions can be reduced by a bonding agent if the metal redox electrode potential $\left(E_{\mathrm{M}}^{+}\right)$is higher than the electrode potential of the bonding agent $\left(E_{\mathrm{B}}^{-}\right)$, which is the main principle of conventional reduction methods. For the preparation of bimetallic NCs by these traditional reduction methods, it is difficult to simultaneously

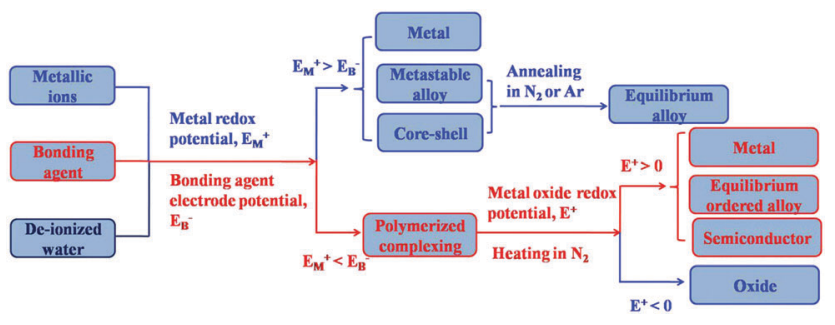

Fig. 7 Schematic illustration of the polymerized complexing method and conventional reduction methods. 
control the reduction and nucleation processes of two distinct metals because of the different redox potentials. ${ }^{28}$ The metallic ions with higher $E_{\mathrm{M}}^{+}$values can be reduced first, and the second metal may deposit on the surface of the first metal, leading to the formation of core-shell NCs. ${ }^{28,29}$ The second metal may also diffuse into the lattice site of the first metal, and then the alloy crystalline phase can be obtained. However, the distributions of the two kinds of metallic atom in the lattice are often random, and so the alloy is often metastable with a disordered crystalline phase. $^{28}$ High temperature annealing should be performed to induce the transition from a disordered phase to an equilibrium ordered crystalline phase. A typical example is the preparation of FePt NCs which have a metastable disordered phase of the as-reduced product and high temperature annealing is required for the formation of FePt NCs with an equilibrium ordered phase. ${ }^{30,31}$ However, NCs will agglomerate and the grain size distribution is very broad. ${ }^{30}$ Two kinds of metallic ion can be reduced very quickly using a strong reducing agent such as $\mathrm{NaBH}_{4}$ and hydrazine hydrate. ${ }^{28}$ However, the reduction rate is difficult to control. ${ }^{28}$ In this polymerized complexing method, $E_{\mathrm{M}}^{+}<E_{\mathrm{B}}^{-}$, the reduction in solution can not take place, and the reducing ability of the bonding agent is prohibited. Instead, the bonding agent can participate in polymerized complexing with mono-, binary-, or ternary-metallic ions, and then the difference between the standard electrode potentials of metallic ions is overcome. If the metal oxide redox electrode potential $\left(E^{+}\right)$is positive, metallic and semiconductor NCs can be obtained, and an equilibrium ordered alloy crystalline phase can be obtained as evidenced by the occurrence of the ordered $\mathrm{Cu}_{3} \mathrm{Pt}$ alloy phase in our previous work. ${ }^{19}$ Therefore, the crystalline phase of alloy NCs can be controlled by this polymerized complexing method. If $E^{+}<0$, reactions (3) and (8) will not take place and the crystalline phase in the calcined product is oxide.

The requirement of $E_{\mathrm{M}}^{+}<E_{\mathrm{B}}^{-}$can be used to direct the search of appropriate bonding agents. For $\mathrm{Ni}$ and $\mathrm{Ag}, E_{\mathrm{B}}^{-}>-0.257 \mathrm{~V}$ and $E_{\mathrm{B}}^{-}>0.7991 \mathrm{~V}$ are required for bonding agents of $\mathrm{Ni}$ and $\mathrm{Ag}$, respectively. Therefore, the range of choice of bonding agents for $\mathrm{Ni}$ is expected to be much broader than that of Ag. This is also consistent with experimental results where various kinds of acid, amine, polyalcohol, and polysaccharide can be used as bonding agents for Ni and only starch, sucrose, and lactic acid can be applied as bonding agents for Ag. ${ }^{19}$ At present, bonding agents with a low reducing ability such as gelatin and starch are used for the preparation of different kinds of semiconductor and metal NC, and it is proposed that more kinds of bonding agent can be discovered in further experiments. For instance, various environmentally friendly plant extracts such as tea extract and coffee extract can be used as reducing agents for the preparation of $\mathrm{Ag}, \mathrm{Au}$, and Pd NCs, ${ }^{32-34}$ meaning that the $E_{\mathrm{B}}^{-}$values of these plants are lower than the metal redox potentials of $\mathrm{Ag}^{+}, \mathrm{Au}^{3+}$, and $\mathrm{Pd}^{2+}$. It is then expected that plant extracts can also be used to prepare other metallic and semiconductor NCs through this polymerized complexing method, and this is verified by the fact that Te NCs can be obtained using the worldwide-popular drinks Coca-Cola and Sprite as bonding agents (Fig. S21 and S22, ESI $\dagger$ ), and subsequent research work is in progress.
According to the calculation results shown in Fig. 5b, it is predicted that $\mathrm{Ru}, \mathrm{Ir}, \mathrm{Os}, \mathrm{Rh}$, and $\mathrm{Au}$ noble metallic NCs can also be obtained because the calculated $\Delta_{\mathrm{f}} G_{\mathrm{m}}^{\varnothing}$ values of these metallic elements are more negative than those of $\mathrm{Ni}, \mathrm{Cu}, \mathrm{Bi}$, $\mathrm{Sb}$, Te, Ag, Pd, and Pt. For the elements As and Se, the calculated values of $\Delta_{\mathrm{f}} G_{\mathrm{m}}^{\varnothing}$ are also negative (Fig. 5b). However, As and Se are semi-metallic elements and their metallicity is lower than that of $\mathrm{Sb}, \mathrm{Bi}$, and Te. Therefore, the preparation of As and Se NCs should be verified by further experimental work. For alloys or compounds, those containing elements of type 1 and type 2 are expected to be obtained by this method, including $\mathrm{Ag}-\mathrm{Pd}, \mathrm{Ag}-\mathrm{Pt}, \mathrm{Ag}-\mathrm{Sb}, \mathrm{Ag}_{2} \mathrm{Se}$ (Fig. 6d), $\mathrm{BiPd}, \mathrm{Bi}_{2} \mathrm{Pd}, \mathrm{Bi}_{2} \mathrm{Pt}$, BiPt, $\mathrm{Bi}_{2} \mathrm{Se}_{3}$ (Fig. 6d), Co-Ni, Co-Pd, CuPt, CuPt ${ }_{3}, \mathrm{Cu}-\mathrm{Sb}$, CuSe (Fig. 6d), $\mathrm{Cu}_{2} \mathrm{Te}, \mathrm{HgTe}^{7}{ }^{\mathrm{NiBi}}, \mathrm{NiBi}_{3}, \mathrm{NiSb}, \mathrm{NiSe}, \mathrm{NiSe}_{2}$ (Fig. 6d), $\mathrm{Sb}_{2} \mathrm{Se}_{3}$ (Fig. 6d), Se-Te, $\mathrm{Cu}-\mathrm{Bi}-\mathrm{Se}, \mathrm{Cu}-\mathrm{Ni}-\mathrm{Pt}$, and $\mathrm{Cu}-\mathrm{Te}-\mathrm{Se}$. Those containing type 3 elements and elements of type 1 and type 2 may also be prepared, such as $\mathrm{CdNi}, \mathrm{Cd}_{5} \mathrm{Ni}, \mathrm{CdSe}$ (Fig. 6d), SnSe (Fig. 6d), and $\mathrm{Ga}_{2} \mathrm{Te}_{3}$ (Fig. 6d) NCs. Compounds consisting of type 3 elements can not be obtained by this method because of the positive $\Delta_{\mathrm{f}} G_{\mathrm{m}}^{\varnothing}$ value.

Furthermore, it is worth noting that this calculation model is based on the reaction between oxide and $\mathrm{H}_{2}$, and the gas of the reaction product is considered to be $\mathrm{H}_{2} \mathrm{O}(\mathrm{g})$. In fact, $\mathrm{CH}_{4}$ and $\mathrm{CO}_{2}$ gases are also detected by mass spectroscopy. ${ }^{19}$ The reaction between oxide and $\mathrm{CH}_{4}$ also occurs, and reaction paths similar to reactions (3) and (8) can also be depicted:

$$
\begin{aligned}
& 4 \mathrm{MO}_{x}+x \mathrm{CH}_{4} \rightarrow 4 \mathrm{M}+ 2 x \mathrm{H}_{2} \mathrm{O}(\mathrm{g})+x \mathrm{CO}_{2}(\mathrm{~g}) \\
& 4 \mathrm{aAO}_{x}+4 \mathrm{bBO}_{y}+(\mathrm{a} x+\mathrm{b} y) \mathrm{CH}_{4} \rightarrow 4 \mathrm{~A}_{\mathrm{a}} \mathrm{B}_{\mathrm{b}}+2(\mathrm{a} x+\mathrm{b} y) \mathrm{H}_{2} \mathrm{O}(\mathrm{g}) \\
&+(\mathrm{a} x+\mathrm{b} y) \mathrm{CO}_{2}(\mathrm{~g})
\end{aligned}
$$

In addition, $\mathrm{C}$ and $\mathrm{CO}$ may also serve as reducing agents, ${ }^{35}$ and similar reaction paths can also be expressed as:

$$
\begin{gathered}
\mathrm{MO}_{x}+x \mathrm{CO}(\mathrm{g}) \rightarrow \mathrm{M}+x \mathrm{CO}_{2}(\mathrm{~g}) \\
\mathrm{aAO}_{x}+\mathrm{bBO}_{y}+(\mathrm{a} x+\mathrm{b} y) \mathrm{CO}(\mathrm{g}) \rightarrow \mathrm{A}_{\mathrm{a}} \mathrm{B}_{\mathrm{b}}+(\mathrm{a} x+\mathrm{b} y) \mathrm{CO}_{2}(\mathrm{~g})
\end{gathered}
$$

and

$$
\begin{gathered}
2 \mathrm{MO}_{x}+x \mathrm{C}(\mathrm{s}) \rightarrow 2 \mathrm{M}+x \mathrm{CO}_{2}(\mathrm{~g}) \\
2 \mathrm{aAO}_{x}+2 \mathrm{bBO}_{y}+(\mathrm{a} x+\mathrm{b} y) \mathrm{C}(\mathrm{s}) \rightarrow 2 \mathrm{~A}_{\mathrm{a}} \mathrm{B}_{\mathrm{b}}+(\mathrm{a} x+\mathrm{b} y) \mathrm{CO}_{2}(\mathrm{~g})
\end{gathered}
$$

The $\Delta_{\mathrm{f}} G_{\mathrm{m}}^{\varnothing}$ values of these reaction paths can also be calculated. For eqn (15) and (16), Bi, $\mathrm{Cu}, \mathrm{Pd}$, and Te remain as type 1 elements, and Pt can also be catalogued as a type 2 element. Ag is considered as a type 1 element. $\mathrm{Ni}$ and $\mathrm{Sb}$ are classified as type 3 elements, and the lower critical temperatures are 420 and $417 \mathrm{~K}$ for $\mathrm{Ni}$ and $\mathrm{Sb}$. Cd is also catalogued as a type 3 element and the corresponding lower critical temperature is $594 \mathrm{~K}$. The calculated $\Delta_{\mathrm{f}} G_{\mathrm{m}}^{\varnothing}$ values for the reaction paths of $\mathrm{Ag}_{2} \mathrm{Te}, \mathrm{Bi}_{2} \mathrm{Te}_{3}$, $\mathrm{Sb}_{2} \mathrm{Te}_{3}$, and CdTe are negative, and all the calculated $\Delta_{\mathrm{f}} H_{\mathrm{m}}^{\varnothing}$ values are negative and $\Delta_{\mathrm{f}} S_{\mathrm{m}}^{\varnothing}$ values are positive. The lower critical temperatures for $\mathrm{Ni}_{3} \mathrm{Sn}$ and $\mathrm{SnTe}$ are 431 and $106 \mathrm{~K}$, and the heating temperatures in our experimental heat treatments 
are higher than these values. When the calculations are based on the reduction of $\mathrm{CO}$ gas (eqn (17) and (18)), $\mathrm{Bi}, \mathrm{Cu}, \mathrm{Ni}$, and $\mathrm{Pd}$ can also be catalogued as type 1 elements. However, Cd is considered as a type 1 element, which is contradictory to the experimental results. Then it is suggested that $\mathrm{CO}$ can not be the main reducing gas in this polymerized complexing method. When the calculations are based on eqn (19) and (20), the corresponding results are the same as the results determined from eqn (15) and (16). Ag and $\mathrm{Pt}$ are considered as type 1 elements. $\mathrm{Ni}$ and $\mathrm{Sb}$ are classified as type 3 elements, and the lower critical temperatures for $\mathrm{Ni}, \mathrm{Sb}, \mathrm{Cd}$, $\mathrm{Sn}$, and SnTe are calculated to be 448, 444, 616, 905, and $142 \mathrm{~K}$ respectively. The calculated $\Delta_{\mathrm{f}} G_{\mathrm{m}}^{\varnothing}$ values for the reaction paths of $\mathrm{Ag}_{2} \mathrm{Te}, \mathrm{Bi}_{2} \mathrm{Te}_{3}, \mathrm{Sb}_{2} \mathrm{Te}_{3}$, CdTe, and $\mathrm{Ni}_{3} \mathrm{Sn}$ are also negative, $\Delta_{\mathrm{f}} H_{\mathrm{m}}^{\varnothing}$ values are negative, and $\Delta_{\mathrm{f}} S_{\mathrm{m}}^{\varnothing}$ values are positive. The overall reaction must take place with the coexistence of $\mathrm{H}_{2}$ and $\mathrm{CH}_{4}$, and $\mathrm{C}$ may also act as a reducing medium, and the occurrence of the $\mathrm{Ni}$ and $\mathrm{Sb}$ crystalline phase in the experimental results is then acceptable. Therefore, it is suggested that the substitution of $\mathrm{H}_{2}$ by $\mathrm{CH}_{4}$ or $\mathrm{C}$ in the calculation equations does not affect the main judgement of this thermodynamical criterion.

\section{Conclusions}

In summary, we have shown the thermodynamical criterion of the environmentally friendly polymerized complexing method for the preparation of Te, CdTe, $\mathrm{Ag}_{2} \mathrm{Te}, \mathrm{CuTe}, \mathrm{NiTe}_{1.5}, \mathrm{Bi}_{2} \mathrm{Te}_{3}, \mathrm{Sb}_{2} \mathrm{Te}_{3}$, and $\mathrm{In}_{2} \mathrm{Te}_{3}$, ternary $\mathrm{Ni}_{2.9} \mathrm{SnTe}_{2}, \mathrm{CuInS}_{2}$, and $\mathrm{CuGaTe}_{2}$ semiconductor NCs, and metallic $\mathrm{Ag}, \mathrm{Cu}, \mathrm{Ni}, \mathrm{Co}, \mathrm{Bi}$, and $\mathrm{Sb}$ NCs. Based on the calculation of $\Delta_{\mathrm{f}} G_{\mathrm{m}}^{\varnothing}, \Delta_{\mathrm{f}} H_{\mathrm{m}}^{\varnothing}$, and $\Delta_{\mathrm{f}} S_{\mathrm{m}}^{\varnothing}$ of the reaction of metal oxides with reducing gases, metallic elements can be divided into three types. The type 1 elements are defined when $\Delta_{\mathrm{f}} G_{\mathrm{m}}^{\varnothing}<0$, $\Delta_{\mathrm{f}} H_{\mathrm{m}}^{\varnothing}<0$, and $\Delta_{\mathrm{f}} S_{\mathrm{m}}^{\varnothing}>0$, type 2 elements correspond to $\Delta_{\mathrm{f}} G_{\mathrm{m}}^{\varnothing}<0, \Delta_{\mathrm{f}} H_{\mathrm{m}}^{\varnothing}<0$, and $\Delta_{\mathrm{f}} S_{\mathrm{m}}^{\varnothing}<0$, and type 3 elements are determined by $\Delta_{\mathrm{f}} G_{\mathrm{m}}^{\varnothing}>0, \Delta_{\mathrm{f}} H_{\mathrm{m}}^{\varnothing}>0$, and $\Delta_{\mathrm{f}} S_{\mathrm{m}}^{\varnothing}>0$. Type 1 and 2 elements can be readily prepared by this method, and $\mathrm{Ni}, \mathrm{Cu}$, $\mathrm{Bi}, \mathrm{Sb}, \mathrm{Te}, \mathrm{Pd}, \mathrm{Pt}$, and Ag are typical elements. Type 3 elements can not be prepared by this method in the temperature range of 623-823 K with only one exception of Cd since $\Delta_{\mathrm{f}} G_{\mathrm{m}}^{\varnothing}<0$ occurs at temperatures higher than $594 \mathrm{~K}$. Those compounds formed by the elements of type 1 and type 2 can also be obtained by this benign and facile process, and compounds consisting of type 1 and 2 elements with type 3 elements can also be prepared if the calculated $\Delta_{\mathrm{f}} G_{\mathrm{m}}^{\varnothing}$ value is negative. The theoretical results of the thermodynamical criterion are in excellent agreement with experimental results and the criterion can be considered as an intrinsic rule for the polymerized complexing method. It is suggested that the controlling factors in the determination of the crystalline phase in the final calcined products are the $\Delta_{\mathrm{f}} G_{\mathrm{m}}^{\varnothing}$ values of the reaction of the reduction of oxide and the metal oxide redox standard electrode potentials, not the electronegativity of the elements and the metal redox standard electrode potentials. Finally, a prediction has been presented for the compounds that can be prepared by this method from the thermodynamical criterion. Our results open up a new approach for the preparation of semiconductor and metallic NCs.

\section{Conflicts of interest}

There are no conflicts to declare.

\section{Acknowledgements}

This work was supported by the National Science Foundation of China (51201090), the China Scholarship Council (CSC), and a project funded by the Priority Academic Program Development of Jiangsu Higher Education Institutions (PAPD). Nguyền Thị Kim Thanh thanks the Royal Society and EPSRC for financial support (EP/M018016/1).

\section{References}

1 V. Lesnyak, N. Gaponik and A. Eychmüller, Chem. Soc. Rev., 2013, 42, 2905-2929.

2 Y. l. Li, L. H. Jing, R. R. Qiao and M. Y. Gao, Chem. Commun., 2011, 47, 9293-9311.

3 S. Q. Lin, W. Li, Z. W. Chen, J. W. Shen, B. H. Ge and Y. Z. Pei, Nat. Commun., 2016, 7, 10287.

4 J. Sun, H. F. Ma, H. Jiang, L. Y. Dang, Q. Y. Lu and F. Gao, J. Mater. Chem. A, 2015, 3, 15882-15888.

5 Y. Y. Jia, Y. Q. Jiang, J. W. Zhang, L. Zhang, Q. L. Chen, Z. X. Xie and L. S. Zheng, J. Am. Chem. Soc., 2014, 136, 3748-3751.

6 A. Sahu, M. S. Kang, A. Kompch, C. Notthoff, A. W. Wills, D. Deng, M. Winterer, C. D. Frisbie and D. J. Norris, Nano Lett., 2012, 12, 2587-2594.

7 K. Yu, X. Y. Liu, T. Qi, H. Q. Yang, D. M. Whitfield, Q. Y. Chen, E. J. C. Huisman and C. W. A. Hu, Nat. Commun., 2016, 7, 122223.

8 B. H. Yan and S. C. Zhang, Rep. Prog. Phys., 2012, 75, 096501.

9 Z. A. Peng and X. G. Peng, J. Am. Chem. Soc., 2001, 123, 183-184.

10 C. B. Murray, D. J. Norris and M. G. Bawendi, J. Am. Chem. Soc., 1993, 115, 8706-8715.

11 D. Yao, Y. Liu, W. J. Zhao, H. T. Wei, X. T. Luo, Z. N. Wu, C. W. Dong, H. Zhang and Y. A. Bai, Nanoscale, 2013, 5, 9593-9597.

12 R. E. Schaak, A. K. Sra, B. M. Leonard, R. E. Cable, J. C. Bauer, Y. F. Han, J. Means, W. Teizer, Y. Vasquez and E. S. Funck, J. Am. Chem. Soc., 2005, 127, 3506-3515.

13 Q. L. Liao, R. Tannenbaum and Z. L. Wang, J. Phys. Chem. B, 2006, 110, 14262-14265.

14 H. R. Yang, S. W. Finefrock, J. D. A. Caballero and R. J. Wu, J. Am. Chem. Soc., 2014, 136, 10242-10245.

15 H. Zhang, M. S. Jin, J. G. Wang, M. J. Kim, D. R. Yang and Y. N. Xia, J. Am. Chem. Soc., 2011, 133, 10422-10425.

16 M. J. Jiang, B. Lim, J. Tao, P. H. Camargo, C. Ma, Y. M. Zhu and Y. N. Xia, Nanoscale, 2010, 2, 2406-2411.

17 J. Zeng, J. Tao, W. Y. Li, J. Grant, P. Wang, Y. M. Zhu and Y. N. Xia, Chem. - Asian J., 2011, 6, 376-379.

18 R. G. Mortimer, Physical Chemistry, Elsevier, 3rd edn, 2008. 19 P. Y. Li, F. S. Li, D. Deng, X. D. Guo, H. Y. Liu, W. Jiang and T. H. Wang, Chem. Commun., 2016, 52, 2996-2999.

20 H. T. Zhu, J. Luo and J. K. Liang, J. Mater. Chem. A, 2014, 2, 12821-12826. 
21 S. S. Garje, D. J. Eisler, J. S. Ritch, M. Afzaal, P. O'Brien and T. A. Chivers, J. Am. Chem. Soc., 2006, 128, 3120-3121.

22 F. Cardarelli, Materials Handbook, Springer, 2nd edn, 2008.

23 D. S. Wang, Q. Peng and Y. D. Li, Nano Res., 2010, 3, 574-580.

24 Y. C. Yan, J. S. Du, K. D. Gilroy, D. Yang, Y. N. Xia and H. Zhang, Adv. Mater., 2017, 29, 1605997.

25 I. I. Barin, Thermochemical Data of Pure Substances, VCH, 3rd edn, 1995.

26 P. Y. Li, G. D. Deng, X. D. Guo, H. Y. Liu, W. Jiang and F. S. Li, J. Alloys Compd., 2016, 668, 159-168.

27 G. 1. Miessler and D. A. Tarr, Inorganic Chemistry, Pearson Education Press, 3rd edn, 2008.
28 D. S. Wang and Y. D. Li, Adv. Mater., 2011, 23, 1044-1060.

29 R. Ferrando, J. Jellinek and R. L. Johnston, Chem. Rev., 2008, 108, 845-910.

30 J. H. He, B. R. Bian, Q. Zheng, J. Du, W. X. Xia, J. Zhang, A. Yan and J. P. Liu, Green Chem., 2016, 18, 417-422.

31 B. R. Bian, J. H. He, J. Du, W. X. Xia, J. Zhang, J. P. Liu, W. Li, C. F. Hu and A. Yan, Nanoscale, 2015, 7, 975-980.

32 S. Iravani, Green Chem., 2011, 13, 2638-2650.

33 R. Mohammadinejad, S. Karimi, S. Iravani and R. S. Varma, Green Chem., 2016, 18, 20-52.

34 J. L. Huang, L. Q. Lin, D. H. Sun, H. M. Chen, D. P. Yang and Q. B. Li, Chem. Soc. Rev., 2015, 44, 6330-6374.

35 Y. F. Shen, J. Mater. Chem. A, 2015, 3, 13114-13188. 